\title{
Development of the Waste Management Composite Index Using DEA Method as Circular Economy Indicator: The Case of European Union Countries
}

\author{
Tijana Milanović ${ }^{1 *}$, Gordana Savić2 Milan Martić $^{2}$, Maja Milanović Nataša Petrović $^{2}$ \\ ${ }^{1}$ Belgrade Academy of Business and Art Vocational Studies, Serbia \\ ${ }^{2}$ University of Belgrade, Faculty of Organizational Sciences, Serbia \\ ${ }^{3}$ Universidad de Valencia, Faculty of Philology, Translation and Communication, Spain
}

Received: 2 April 2021

Accepted: 4 June 2021

\begin{abstract}
This paper aims to develop a Waste Management Composite Index (WMCI) as a Circular Economy (CE) indicator by using a DEA-based model. This approach will enable making a mutual comparison, i.e. comparative analysis of the countries CE performances. Even though many countries have already accomplished a great deal in terms of the $\mathrm{CE}$, there are still numerous of those that have not progressed much, finding themselves at the very beginning of the process. For that matter, the development of the indicators would help monitor changes during the transition process and while shifting to the CE model.

In this paper, a tailor-made DEA model is created to fit a two-layer composite index WMCI comprising of eight relevant sub-indicators. The model is applied for the comparison of the 26 European Union (EU) countries. The obtained results could help maintain the countries informed about their position on the ranking list, alongside the level of their implementation of the $\mathrm{CE}$ with guidelines and recommendations for possible future development in this area.
\end{abstract}

Keywords: circular economy, waste management, DEA method, composite index

\section{Introduction}

Accelerated social progress and the pursuit of profit have led to a global economic and environmental crisis, reflected in the increasing waste of energy and resources and the accumulation of increasing amounts of waste. This type of economy, that is, conversion of natural resources into waste, can be defined as a linear economy and it leads to environmental degradation,

*e-mail: tijana.milanovic@bpa.edu.rs reducing natural capital from the environment and affecting the value of natural capital that is polluted from waste [1]. However, better use of natural resources, especially waste and residues, can bring economic and environmental benefits [2]. Also 'natural resources mean key characteristics of the environment required to the sustainable economic development and have a great value for the humankind' [3].

The CE concept implies the complete usage of all resources, as well as one of the solutions that must be introduced to regulate enormous amounts of waste since it returns waste to the production process and generally involves all segments of an economy. 
Economic, environmental and many other benefits can be achieved by minimizing the amount of waste generated, through recycling and reuse of products [4]. The CE concept should create a system of production and consumption with minimal material and energy losses through reuse, recycling and recovery [5]. This development strategy, according to [6], maximizing resource efficiency and minimizing waste production, maintains the value of products, materials and resources within the economy for as long as possible [7] and 'it is important for energy waste and the greenhouse effect to take the necessary treatment' [8]. Nevertheless, the transition to the CE concept is not an easy task and to monitor and further develop the complexity of properly applying this model, it is necessary to develop indicators that would facilitate its application alongside with its principles. The possibility of measuring the $\mathrm{CE}$ at the national level is of paramount importance, since the 'CE is a key driver of sustainable growth' and development [9]. Thus, it has been done a lot on the development of circularity indicators in recent years $[10,11]$.

Setting the indicators and finding simple ways to measure the values, further facilitate the assessment process and all this allows the analysis of different options for waste resources recovery [12]. Furthermore, measuring the performance of waste management is vital for policymakers and scientists, to show them whether the EU countries are on the 'right' path to the $\mathrm{CE}$ and what is their efficiency in the field of resources, waste, raw materials and other areas [13]. The EU countries have developed ten indicators in four areas, one of which is waste management. By applying and combining these indicators, it is possible to develop a composite indicator $[12,13]$. According to the authors Mitrović and Veselinov [14], the importance in the development of composite indicators is 'a useful tool in the analysis of policies and public communications' [15]. The development of composite indicators proved to be 'purposeful and important' when it comes to comparing countries in terms of levels of development in different areas $[14,16]$. As aforementioned, this paper focuses on the $\mathrm{CE}$ indicators related to waste management and developed by the EU.

The DEA method has been successfully demonstrated in practice for the development of a composite index. In the last twenty years, the DEA has proven to be one of the most successful operational research methods for evaluation the non-profit and profit organizations efficiencies, 'as a suitable tool for efficiency assessment of the economic and environmental performance' [17], but it is also an appropriate method for developing a composite indicator $[18,19]$.

This paper aims to use the DEA method to develop a waste management composite index use it for analysis within the EU countries. This composite index shows the current state of each country during the transition to the $\mathrm{CE}$ and allows comparison and ranking of the EU countries. The development of a composite index is also important because it enables us to see the precise progress of a certain EU country during the transition and application of the CE principles and where it currently stands in terms of adopting the CE models.

The structure of the paper is as follows. Section 2 introduces a review of development of waste management indicators within the European Union. In Section 3, review of the composite indices development literature the DEA method in the Waste Management field is introduced. In Section 4, Methodology, the DEA method with its estimations is recalled. In Section 5, review of indicators and sub-indicators selection is introduced. The results, discussion and experimental results are presented in Section 6. A final conclusion on completes the paper is given in Section 7.

\section{Development of Waste Management Indicators within the European Union}

Considering that there are numerous CE definitions, a wide range of CE indicators has also been developed, which differ according to the criteria they are based upon [8].

In the last couple of years, within the EU the importance to this issue has been given increasingly alongside with the concerns regarding the sustainability, which all entails a growing need for the introduction of CE, as well as monitoring its performance in all countries [9]. EU goals, include the greater responsibility in natural resources management, and therefore, over-exploitation of resources should be avoided; the efficiency of use of natural resources should be improved; the value of services provided by the ecosystem should be recognized' [20]. Although the EU has been focusing on sustainable development through the development and implementation of various strategies, action plans and documents for years, the concept of $\mathrm{CE}$ is still a somewhat new approach. In 2015, the EU developed the Circular Economy Action Plan intending to provide a regulatory framework for CE development, as well as formulating clear indicators on the way to achieving long-term waste management goals [21]. These indicators cover four areas, based on which ten indicators have been identified $[10,22]$. The developed areas include Production and consumption; Waste management; Secondary Raw Materials; and Competitiveness and Innovation.

Furthermore, the essence of CE implemented in the EU is based on Waste management and its central role in applying this model [21], alongside with a hierarchy establishing and waste minimizing. However, it is also essential to value the materials and try to keep the products in use as long as possible, and to be used to create further value in the economy [7]. Today, only about $40 \%$ of household waste in the EU is being recycled. This average does not show a wide variation between the member states and regions, with rates as high as $80 \%$ in some areas and lower than $5 \%$ in others 
[23]. But, as aforementioned, the waste management area is the primacy in the EU, i.e. it has a central role in the application of $\mathrm{CE}$, having in mind that 'reduction of waste generation, reuse and new products from waste materials are priorities of CE [24]. This is one of the reasons why this area is given priority in choosing indicators and further developing composite $\mathrm{CE}$ indicator. Furthermore, a review of the literature, presented below, shows that a composite indicator of the waste management has not been developed so far at the level of all indicators, within that field, at the EU countries level. Although the work has been done in the field of developing a composite indicator, by using mainly one type of waste, e.g., the municipal one, which means not considering the entire waste management field. Also, many companies report inconsistent waste data, often lacking effective indicators to measure and promote resource reduction and reuse [25].

\section{Composite Indices in the Waste Management Area and the DEA Method}

The set of individual indicators, assigned an aggregate index with appropriate weighting coefficients, is a composite index. Its specificity is that can measure multidimensional concepts which cannot be covered by a single indicator $[18,26]$. Different methods, such as factor analysis, analysis of main components, weighted sum method, can be used to form composite index. The formation of composite indicators is possible by the DEA method [27, 28]. The DEA is useful for overcoming certain significant limitations, such as the undesired dependence of the results of the previous normalization of indicators or subjectivity in the formation of weighting coefficients [28]. In recent years, there has been significant growth in the use of composite indices to assess the performance of countries and institutions in several areas [9, 29, 30]. The development of composite indicators in the field of $\mathrm{CE}$ and sustainability using the DEA method was significantly related to the examples coming from EU countries. Meaning that composite indicators have become a very useful tool when comparing the performance of the member states [18]. Moreover, the DEA method was used to develop a composite indicator Circular Economy Index (CEI), based on three areas, such as: Sustainable Resource Management Index (SRMI), Social Behavior Index (SBI) and Business Operations Index (BOI), to calculate the efficiency of the EU countries and thus perform their ranking [31]; and to rank the EU countries and measure their competitiveness, based on the development of the composite indicator Green Economy Development Index (GEDI) [32], as well as the Circular Economy Index (CEI) [14]. Regarding the scope of provinces, cities and municipalities, an example of developing a composite indicator Circular Economy Index System was presented by $\mathrm{Li}$ and $\mathrm{Xu}$ [33], where they calculated the level of development efficiency from 1995 to 2005 in Sichuan Province in China, based on the DEA method.
A further example, related to the Chinese province and cities, is the development of the composite indicator CE Efficiency Assessment Index based on the DEA method, electricity consumption by regions and fixed capital investment in cities and provinces in eastern China 2011-2017 [34]. Regarding the ranking of cities according to environmental efficiency, by combining the DEA method and Shannon's entropy method, a composite indicator was developed to calculate the environmental efficiency of a city, through cost efficiency assessment of 108 major Italian municipalities [35]. More specifically, in the waste management field, the DEA method was used to assess the environmental efficiency of 28 EU member states [36]. Combination of DEA, Life cycle analysis (LCA) and post-incorporation processes was used to assess the impact of food waste on the environment by analyzing 12 environmental indicators [37].

Furthermore, a modified DEA method was used for assessment of the environmental impact, including the unsorted waste as undesirable output that should be minimized, and to estimate the costs in municipal waste management systems, using the data from 289 municipalities and regions, in between 2011 and 2013 [38]. Also, the DEA method, alongside with Exploratory Data Analytics (EDA), has found application to develop a composite indicator for efficient and sustainable construction waste management and of 28 EU countries for the period 2010-2016 [39]; then, to assess performance in the treatment of municipal waste of 27 EU member states, for the period 1995-2016, with a composite performance indicator developed based on the DEA method and multi-territorial decision technique - including landfill, incineration, recycling and composting and digestion as treatment [40]. Regarding municipal waste, another composite index - Aggregate Indicator (AI) was developed to assess the efficiency of municipal waste collection [41]. Since the unwanted residues or outputs are also considered a type of waste, therefore in this context, the DEA has been applied for the analysis of the treatment of 'undesirable' resultsoutputs [33], as well as for developing a composite indicator as a scale for measuring the undesirable results of Brazilian hydropower plants [42]. Moreover, when it comes to sustainable energy, by combining the MCDA-DEA method (multi-criterion decision analysis - data envelopment analysis) a composite Sustainable Energy Indicator for 109 countries worldwide in the period 2005-2010 [43] was also developed.

Also, one of the most recent works is in the field of municipal waste management and exploitation, and the DEA method was applied to rank EU countries based on their environmental performance and CE performance [13]. The composite indicator SPI (Social Progress Index) was developed with the DEA method, based on three areas: Basic Human Needs; Foundations of Wellbeing and Opportunity, and based on twelve indicators. The indicators included in the model are presented within the two types of models: the first 
are Environmental performance models (inputs are: MSW generated; Basic human needs; Foundations of wellbeing; Opportunity. The output is Recycling rate of MSW). Whereas, the second type are Circular economy performance models (inputs are: MSW generated; Basic human needs; Foundations of wellbeing; Opportunity; The outputs are Recycling rate of MSW and Circular material use rate).

Finally, based on this review, it can be concluded that a general composite indicator, covering all indicators contained within the waste management field, has not been developed for the EU countries yet. Most of the work is focused on separate indicators, such as municipal, construction waste, so the development of a composite indicator $\mathrm{CE}$ at this level is of great importance for further monitoring.

\section{Methodology}

This research aims to create the WMCI based on the DEA method. The composite index comprises several indicators into one performance measure and involves setting the assumptions regarding normalization, aggregation, and weighting usually done on an ad-hoc basis.

Therefore, nonparametric DEA methods have been proposed as means to avoid a priori assumptions and subjectivity in the composite index development process $[18,28,44,45,47]$. The DEA is a linear programming technique introduced by Charnes, Cooper and Rhodes [46] for measuring the efficiency of non-profit units. Originally, the DEA technique creates an aggregate index by maximizing the ratio of a weighted sum of multiple outputs over a weighted sum of multiple inputs, simultaneously liberating the decision-makers from enforcing any judgment on their relative importance [13]. Due to those advantages and flexibility, this method has been implemented in various areas for performance evaluation of similar units such as banking, education, energy, agriculture or the public sector [48]. However, for the composite index construction, only inputs or outputs of the DMUs will be taken into account in the model for aggregating a set of individual indicators [45]. According to the DEA model, each DMU obtains its own best possible indicator weights to achieve the best possible performance measure in comparison to all other units in the observing set. Such a model (1-3) is known as the 'benefit of the doubt' (BOD) approach [28]. Suppose that we have a set of indicators $I$, with values $y_{r j} k \in N$, $\forall j \in N$, need to be aggregated into composite index $h_{k}$, which evaluate performance of DMUk in comparison with other DMUj in the observing set $N$, (Eq. 2). The model (1-3) should be solved once for each DMUj, $\forall j \in N$. As a result, composite index values $h_{k} k \in N$, together with weights $u_{r,} \forall r \in I$ will be obtained for each $\mathrm{DMU}_{k}$.

$$
(\max ) h_{k}=\sum_{r \in I} u_{r} y_{r k}
$$

s.t.

$$
\begin{gathered}
\sum_{r \in I} u_{r} y_{r j} \leq 1, \quad \forall j \in N \\
u_{r} \geq 0, \forall r \in I
\end{gathered}
$$

The WMCI consists of two indicators and several sub-indicators (Table 1). Hence, this is an example of a multi-layer composite indicator [45]. To comprise two-layers index composition and provide better discrimination among DMUs, we proposing the model (1-5) as a modification of the DEA BOD model using the following notations:

$N$ - set of DMUs;

$L-$ a set of indicators;

$I_{l}$ - a set of sub-indicators create an indicator $l \in L$.

$a_{l}$ - upper bound of the performance level for an indicator $l, 0 \leq a_{l} \leq 1, l \in L_{2}$ imposed by decision-maker; under the condition that $\sum_{\forall l \in L} a_{l} \geq 1$ to ensure feasible solution [46]. $B, U_{r}$ - lower and upper bound of the performance level for an sub-indicator $r$, imposed by decision-maker; under the conditions that $\sum_{r \in \bigcup_{\forall l \in L} I_{l}} B_{r} \leq 1, \sum_{r \in \bigcup_{\forall l \in L} I_{l}} U_{r} \geq 1$.

$$
(\max ) C I_{k}=\sum_{r \in \bigcup_{\forall l \in L} I_{l}} u_{r} y_{r k}
$$

s.t.

$$
\begin{gathered}
\sum_{r \in \bigcup_{\forall l \in L} I_{l}} u_{r} y_{r j} \leq 1, \quad \forall j \in N \\
\sum_{r \in R_{l}} u_{r} y_{r k} \leq a_{l}, \forall l \in L \\
B_{r} \leq u_{r} y_{r k} \leq U_{r}, \forall r \in \bigcup_{\forall l \in L} I_{l} \\
u_{r} \geq 0, \forall r \in \bigcup_{\forall l \in L} I_{l}
\end{gathered}
$$

The objective function (Eq. 4) evaluates WMCI $\left(C I_{k} \leq 1, k \in N\right)$, as an weighted sum of sub-indicators $\sum_{r \in \bigcup_{\forall l \in L} I_{l}} u_{r} y_{r k}$ DMUj,$(\forall j \in N)$ (Eq. 2).

The constrains given by Eqs (6) and (7) allow indicators $\left(\sum_{r \in R_{l}} u_{r} y_{r k}, \forall l \in L\right)$ and sub-indicators $\left(u_{r} y_{r k}, \forall r \in \bigcup_{\forall l \in L} I_{l}\right)$ calculation. The virtual indicator value shows the relative contribution of each indicator or sub-indicator to the composite index. Those levels could be restricted subjectively by decision-makers as 
Table 1. Area/ Topic, indicators and sub-indicators.

\begin{tabular}{|c|c|c|}
\hline $\begin{array}{l}\text { Area/ Topic } \\
\text { Composite index }\end{array}$ & Indicators & Sub-indicators \\
\hline \multirow[b]{2}{*}{$\begin{array}{l}\text { Waste management } \\
\text { (WMCI) }\end{array}$} & Recycling rates (RRI) & $\begin{array}{l}\text { Municipal waste recycling rate (I1) } \\
\text { Recycling rate of total waste excluding mineral waste (I2) }\end{array}$ \\
\hline & $\begin{array}{l}\text { Recycling for specific } \\
\text { waste streams (RSWSI) }\end{array}$ & $\begin{array}{c}\text { Recycling rate of total packaging waste. (I3) } \\
\text { Recycling rate of plastic packaging waste. (I4) } \\
\text { Wood packaging recycling rate. (I5) } \\
\text { Recycling rate of electrical and electronic waste (e-waste). (I6) } \\
\text { Recycling of biowaste per capita. (I7) } \\
\text { Recovery rate of construction and demolition waste. (I8) }\end{array}$ \\
\hline
\end{tabular}

Source: Authors' presentation according to EC, 2018 [53]

in GAR DEA models [50], or by setting data-driven bounds [51, 52]. Finally, in this paper, we are applying a decision-maker restriction-based model to overcome the issue of neglecting less favorable indicators by assigning zero weight values (Eqs (6) and (7)).

\section{Indicators and Sub-Indicators Selection}

This section aims to briefly describe and explain the indicators as well as sub-indicators developed by the EU in the Waste management area. Furthermore, they will be used to obtain the composite CE index in the same area (WMCI). Therefore, the circularity indicators (Recycling rate - RRI and Recycling for specific waste streams - RSWSI) and eight subindicators, as well as their hierarchy used in this paper are presented in Table 1.

The values for these eight sub-indicators for following years: 2010, 2012, 2014 and 2016 from 26 EU countries were analyzed based on available data obtained from the Eurostat [53]. However, the data for Croatia were available only for the years 2014 and 2016. The analysis of data for these eight sub-indicators shows that the Netherlands is in the list of countries with the highest values for five sub-indicators, and Belgium for four. Malta is in the list of countries with the lowest values for seven sub-indicators, and Cyprus and Romania for four each. Table 2 shows descriptive statistics for eight sub-indicators.

\section{Municipal Waste Recycling Rate (I1)}

Municipal waste is mainly waste originated from households and other sources, similar in nature and composition to household waste. This sub-indicator Municipal Waste recycling rate is part of the RRI indicator and 'measures the share of recycled municipal waste within the total amount of generated municipal waste' [53]. This sub-indicator provides a good quality index of the overall waste management system. Moreover, its implementation demonstrates the way to use waste as a resource within the CE [53]. According to the Eurostat data, the Municipal waste recycling rate for the $26 \mathrm{EU}$ countries covered by the analysis has been constantly growing as it is shown in Table 2 .

According to this sub-indicator, the countries that have done their best work are Germany (average value 65.1\%), Austria and Belgium, alongside the Netherlands, had always had a Municipal waste recycling rate over $50 \%$. On the other hand, the countries with the lowest value are Malta (average value 7.3\%), Slovakia, Cyprus and Romania, having always had, rate under $20 \%$.

\section{Total Waste Recycling Rate Excluding Mineral Waste (I2)}

This sub-indicator is also part of the RRI and is obtained as a percentage of the amount of recycled waste in the total treated waste. The relevance of this sub-indicator is reflected in the direct monitoring of the amount of material returned to the economy [53]. The average value of $\mathrm{I} 2$ for $26 \mathrm{EU}$ countries covered by the analysis was in constant growth, but milder than the I1 was (Table 2). The best-ranked countries are Belgium (average value 78.5\%), as well as and Luxembourg, the Netherlands and Slovenia (over $70 \%$ in the whole period). The countries with the lowest value of this subindicator (below 30\%) are Estonia, Bulgaria, Romania and Malta.

\section{Recycling Rate of Total Packaging Waste (I3)}

Recycling rate of total packaging waste is part of the RSWSI, and 'represents the share of recycled packaging waste in the total generated packaging waste' [53]. Packaging waste is divided into plastic packaging waste and wood waste, meaning it includes these two sub-indicators [53]. The Directive on packaging and packaging waste, which defines the objectives of recycling, has had a major impact on waste management across the EU [54]. The average value of this subindicator for the countries covered by the analysis are given in Table 2. This sub-indicator has also shown the constant growth. Furthermore, the best-ranked countries within this time period and according to this indicator are Belgium (average value $80.8 \%$ ), Denmark, the Czech Republic, the Netherlands and Germany (average value over $70 \%$ ). The countries with the lowest 
Table 2. Descriptive statistics of sub-indicators.

\begin{tabular}{|c|c|c|c|c|c|c|c|c|c|}
\hline & Year & $\mathrm{I} 1[\%]$ & $\mathrm{I} 2[\%]$ & $\mathrm{I} 3[\%]$ & I4 [\%] & $\mathrm{I} 5[\%]$ & I6[\%] & I7 [kg] & I8[\%] \\
\hline \multirow{4}{*}{ Min } & 2010 & 4.90 & 22.00 & 28.50 & 20.10 & 2.70 & 11.50 & 0.00 & 0.00 \\
\hline & 2012 & 9.70 & 14.00 & 41.40 & 21.90 & 0.80 & 9.90 & 5.00 & 12.00 \\
\hline & 2014 & 7.40 & 17.00 & 41.30 & 24.60 & 0.40 & 11.50 & 0.00 & 32.00 \\
\hline & 2016 & 7.00 & 10.00 & 39.70 & 23.50 & 0.00 & 15.90 & 0.00 & 54.00 \\
\hline \multirow{4}{*}{ Max } & 2010 & 62.50 & 87.00 & 84.00 & 67.30 & $167.20^{*}$ & 55.30 & 182.00 & 100.00 \\
\hline & 2012 & 65.20 & 80.00 & 80.30 & 64.80 & 82.30 & 62.60 & 196.00 & 100.00 \\
\hline & 2014 & 65.60 & 81.00 & 81.30 & 69.30 & $131.50^{*}$ & 68.30 & 175.00 & 100.00 \\
\hline & 2016 & 67.10 & 80.00 & 81.90 & 74.40 & $103.40 *$ & $105.20 *$ & 181.00 & 100.00 \\
\hline \multirow{4}{*}{ Average } & 2010 & 29.83 & 48.36 & 60.47 & 34.76 & 45.05 & 27.29 & 54.04 & 69.68 \\
\hline & 2012 & 33.15 & 49.80 & 62.90 & 38.13 & 40.14 & 31.77 & 58.40 & 77.64 \\
\hline & 2014 & 34.41 & 50.12 & 63.13 & 41.47 & 39.73 & 35.85 & 59.50 & 83.04 \\
\hline & 2016 & 38.62 & 51.65 & 65.16 & 43.37 & 41.28 & 45.37 & 68.23 & 88.00 \\
\hline \multirow{4}{*}{ St. Dev } & 2010 & 17.12 & 16.04 & 12.46 & 11.07 & 35.05 & 10.43 & 51.33 & 31.38 \\
\hline & 2012 & 15.40 & 17.12 & 8.68 & 11.34 & 21.67 & 12.94 & 51.01 & 27.19 \\
\hline & 2014 & 14.90 & 16.60 & 8.57 & 11.72 & 28.56 & 13.02 & 48.76 & 19.93 \\
\hline & 2016 & 14.60 & 16.54 & 8.77 & 13.01 & 26.57 & 19.53 & 49.05 & 13.58 \\
\hline
\end{tabular}

Source: Authors' calculation.

* Sweden for wood packaging recycling rate in 2010, also Portugal in 2014 and 2016, as well as Bulgaria for e waste in 2016 had continuously high amounts of historic waste. These resulted in high percentage of collection and recycling rate (over $100 \%)$. All of mentioned countries in according with the national targets carried out collection campaigns to solve these problems. These amounts of waste are considered as an exceptional [53].

value of this sub-indicator are Malta and Poland (below $50 \%$ ), as well as Hungary, Romania, and Croatia.

\section{Recycling Rate of Plastic Packaging Waste (I4)}

Recycling rate of plastic packaging waste is part of the RSWSI, and is used in the EU to monitor the target of packaging recycling, from $55 \%$ to 2025 , set in the Action Plan, by the EU Commission [53]. The average value of this sub-indicator for the countries covered by the analysis for 2010 was $34.76 \%$; for 2012, 38.13\%; for $2014,41.47 \%$ and for 2016 it was $43.37 \%$ (Table 2). The best ranked countries in this period according to this sub-indicator are Slovenia and the Czech Republic (average value over 55\%), as well as Slovakia and Lithuania. Whereas, the countries with the lowest value of this sub-indicator are Finland, France, Malta, Poland, and Estonia (below 50\%).

\section{Wood Packaging Recycling Rate (I5)}

Wood packaging recycling rate is also the part of the RSWSI. The EU Commission has proposed achieving $75 \%$ of the 2030 target for the preparation, reuse and recycling of wood packaging, in order to monitor progress in packaging recycling set out in the Action Plan [53]. When it comes to the average value of this sub-indicator for the countries covered by the analysis for 2010 it was $45.05 \%$; for $2012,40.14 \%$; for 2014, 39.73\% and for 2016, 41.28\% (Table 2). However, this is the only one of the eight sub-indicators that has not recorded the growth within the monitored period. Furthermore, the best ranked countries are Portugal, Ireland, and Sweden (average value over 75\%), as well as Belgium and Denmark. On the other hand, the countries with the lowest value of this sub-indicator are Croatia, Malta, Cyprus (average value below 10\%) and Finland.

\section{Recycling Rate of Electrical and Electronic Waste (E-Waste) (I6)}

Electronic and electrical waste is 'the fastestgrowing category of hazardous solid waste in the world' [55]. It is also known as e-waste and apart from that it contains valuable materials. This sub-indicator is part of the RSWSI and is obtained by multiplying the 'collection rate' with 'reuse and recycling rate', which is further expressed in percentage [53]. This is the subindicator that records the highest growth in the Waste Management area (Table 2). The best-ranked countries are Bulgaria, Croatia, and Sweden (average value over $55 \%$ ), as well as, Estonia, Slovakia and Lithuania. The countries with the lowest value of this sub-indicator are 
Malta, Cyprus and Romania (average value below 20\%).

\section{Recycling of Biowaste per Capita (I7)}

One of the wastes that is especially important is biowaste coming from households. This is due to the fact that this kind of a waste is often mixed with other types of waste and further disposed of to the landfills, which consequently leads to a significant climate change and damage.

Therefore, the relevance of this sub-indicator is in emphasizing the importance of the waste composting, i.e., of anaerobic digestion process as a contribution to the CE goals for municipal waste. The sub-indicator is a part of RSWSI and it is indirectly measured as the ratio of composted waste to the total population [53]. The average value of this sub-indicator for the countries covered by the analysis for 2010 was 54.04\%; for $2012,58.4 \%$; for $2014,59.5 \%$ and for 2016 it was
$68.23 \%$. Speaking of the countries, the best-ranked ones are Austria (average value $183.5 \mathrm{~kg}$ per capita), the Netherlands, Denmark and Luxembourg (above $125 \mathrm{~kg}$ per capita). On the other hand, the countries with the lowest value of this sub-indicator are: Malta, Croatia, Poland and the Czech Republic (below $12 \mathrm{~kg}$ per capita).

\section{Recovery Rate of Construction and Demolition Waste (I8)}

Waste from construction and demolition is 'one of the largest sources of waste in Europe' [53]. Hence, the sub-indicator is 'the ratio of construction waste and demolition waste prepared to be reused, recycled or susceptible to material recovery' [53] and it is a part of RSWSI. Even though there are many materials that can be recycled or reused, reuse and recycling rates currently vary widely across the EU [53]. Still, this is the sub-indicator that has the highest values of all

Table 3. Waste management composite index.

\begin{tabular}{|l|l|l|l|l|l|}
\hline Country & WMCI & WMCI & WMCI & WMCI \\
& 2010 & 2012 & 2014 & 2016 & Trend \\
\hline Austria & 1.0000 & 1.0000 & 1.0000 & 1.0000 & \\
\hline Belgium & 1.0000 & 1.0000 & 1.0000 & 1.0000 & \\
\hline Bulgaria & 0.6200 & 0.5780 & 0.5480 & 0.8610 & \\
\hline The Czech Rep. & 0.8100 & 0.8870 & 0.9620 & 0.9550 & \\
\hline Denmark & 1.0000 & 0.9660 & 1.0000 & 1.0000 & \\
\hline Estonia & 0.3980 & 0.5020 & 0.7370 & 0.5310 & \\
\hline Finland & 0.6460 & 0.7050 & 0.7840 & 0.8170 & \\
\hline France & 0.7390 & 0.7900 & 0.8080 & 0.8240 & \\
\hline Netherlands & 1.0000 & 1.0000 & 1.0000 & 1.0000 & \\
\hline Croatia &. & & 0.6920 & 0.8510 & \\
\hline Ireland & 0.8540 & 0.9690 & 0.9960 & 0.9160 & \\
\hline Italy & 0.8980 & 0.9950 & 0.9820 & 0.9170 & \\
\hline Cyprus & 0.5200 & 0.5200 & 0.4970 & 0.4940 & \\
\hline Lithuania & 0.3870 & 0.8530 & 0.9870 & 1.0000 & \\
\hline Luxembourg & 1.0000 & 0.9790 & 0.9510 & 0.9680 & \\
\hline Hungary & 0.5730 & 0.6320 & 0.7930 & 0.8480 & \\
\hline Malta & 0.2600 & 0.3580 & 0.2840 & 0.4410 & \\
\hline Germany & 1.0000 & 1.0000 & 1.0000 & 1.0000 & \\
\hline Poland & 0.6870 & 0.7180 & 0.8650 & 0.8440 & \\
\hline Portugal & 0.6830 & 0.8970 & 1.0000 & 0.9370 & \\
\hline Romania & 0.2950 & 0.4560 & 0.3900 & 0.4110 & \\
\hline Slovakia & 0.5300 & 0.7230 & 0.6380 & 0.7970 & \\
\hline Slovenia & 0.8880 & 1.0000 & 1.0000 & 1.0000 & \\
\hline Spain & 0.7230 & 0.8640 & 0.8120 & 0.7930 & \\
\hline Sweden & 1.0000 & 1.0000 & 1.0000 & 0.9510 & \\
\hline Great Britain & 0.8980 & 0.9400 & 0.8820 & 0.9310 & \\
\hline Sure \\
\hline
\end{tabular}

Source: Authors' calculation. 
within the monitored time period (Table 2). Therefore, the best-ranked are the Netherlands (average value 100\%), Luxembourg, Italy and Ireland and (above 97\%). On the other hand, the countries with the lowest value are Cyprus, Belgium, Finland and Slovakia (below $55 \%)$.

\section{Results and Discussion}

This paper compares WMCI of 26 EU countries by employing BOD DEA model (1-3) and (4-8). The model (4-8) is adopted and modified to suit to the realistic evaluation of waste management composite index. The results are obtained by using custom made MS Excel VBA application and solver.

\section{Experimental Results}

The procedure of WMCI calculation for $26 \mathrm{EU}$ countries is conducted by creating different scenarios. Firstly, in Scenario 1 we employed BOD DEA model (1-3). Upon analyzing the obtained results, we could say that this model does not seem suitable for the formation of a composite index since it enables those countries with a high value of one or two indicators, and minimum values of all other indicators, to be assessed and categorized as efficient. For example, in

Table 4. Recycling rates (RRI) and Recycling specific waste streams (RSWSI) indicators.

\begin{tabular}{|c|c|c|c|c|c|c|c|c|}
\hline \multirow{2}{*}{ Country } & \multicolumn{4}{|c|}{ RRI } & \multicolumn{4}{|c|}{ RSWSI } \\
\hline & 2010 & 2012 & 2014 & 2016 & 2010 & 2012 & 2014 & 2016 \\
\hline Austria & 0.4863 & 0.5000 & 0.5000 & 0.5000 & 0.5137 & 0.5000 & 0.5000 & 0.5000 \\
\hline Belgium & 0.5000 & 0.5000 & 0.5000 & 0.5000 & 0.5000 & 0.5000 & 0.5000 & 0.5000 \\
\hline Bulgaria & 0.3000 & 0.3000 & 0.3000 & 0.3000 & 0.3199 & 0.2775 & 0.2483 & 0.5611 \\
\hline The Czech Rep. & 0.3000 & 0.3000 & 0.3000 & 0.3000 & 0.5100 & 0.5867 & 0.6621 & 0.6550 \\
\hline Denmark & 0.3000 & 0.3000 & 0.4546 & 0.5000 & 0.7000 & 0.6657 & 0.5454 & 0.5000 \\
\hline Estonia & 0.3000 & 0.3000 & 0.3000 & 0.3000 & 0.0979 & 0.2018 & 0.4369 & 0.2306 \\
\hline Finland & 0.3000 & 0.3000 & 0.3000 & 0.3000 & 0.3463 & 0.4045 & 0.4843 & 0.5169 \\
\hline France & 0.3766 & 0.3357 & 0.3333 & 0.3068 & 0.3624 & 0.4545 & 0.4749 & 0.5172 \\
\hline Netherlands & 0.5000 & 0.5000 & 0.5000 & 0.5000 & 0.5000 & 0.5000 & 0.5000 & 0.5000 \\
\hline Croatia & . & . & 0.3000 & 0.3000 & . & . & 0.3916 & 0.5507 \\
\hline Ireland & 0.3000 & 0.3000 & 0.3000 & 0.3000 & 0.5538 & 0.6692 & 0.6959 & 0.6160 \\
\hline Italy & 0.3000 & 0.3000 & 0.3819 & 0.3000 & 0.5984 & 0.6950 & 0.6006 & 0.6169 \\
\hline Cyprus & 0.3000 & 0.3000 & 0.3000 & 0.3000 & 0.2202 & 0.2203 & 0.1975 & 0.1941 \\
\hline Lithuania & 0.3000 & 0.3000 & 0.3000 & 0.5000 & 0.0871 & 0.5530 & 0.6871 & 0.5000 \\
\hline Luxembourg & 0.5000 & 0.4629 & 0.3000 & 0.3000 & 0.5000 & 0.5166 & 0.6515 & 0.6678 \\
\hline Hungary & 0.3000 & 0.3000 & 0.3000 & 0.3477 & 0.2726 & 0.3316 & 0.4934 & 0.5000 \\
\hline Malta & 0.2605 & 0.3000 & 0.2844 & 0.3000 & 0.0000 & 0.0581 & 0.0000 & 0.1406 \\
\hline Germany & 0.4190 & 0.3463 & 0.3218 & 0.3000 & 0.5810 & 0.6537 & 0.6782 & 0.7000 \\
\hline Poland & 0.3000 & 0.3000 & 0.3000 & 0.3000 & 0.3869 & 0.4185 & 0.5655 & 0.5440 \\
\hline Portugal & 0.3000 & 0.3000 & 0.3467 & 0.3000 & 0.3829 & 0.5968 & 0.6533 & 0.6366 \\
\hline Romania & 0.2950 & 0.3000 & 0.3000 & 0.3000 & 0.0000 & 0.1559 & 0.0905 & 0.1113 \\
\hline Slovakia & 0.3000 & 0.3000 & 0.3000 & 0.3000 & 0.2301 & 0.4226 & 0.3382 & 0.4969 \\
\hline Slovenia & 0.3000 & 0.4979 & 0.4287 & 0.5000 & 0.5875 & 0.5021 & 0.5713 & 0.5000 \\
\hline Spain & 0.3000 & 0.3000 & 0.3000 & 0.3000 & 0.4230 & 0.5643 & 0.5120 & 0.4933 \\
\hline Sweden & 0.4714 & 0.3790 & 0.3286 & 0.3348 & 0.5286 & 0.6210 & 0.6714 & 0.6164 \\
\hline Great Britain & 0.3302 & 0.4838 & 0.4719 & 0.4129 & 0.5676 & 0.4561 & 0.4104 & 0.5182 \\
\hline
\end{tabular}

Source: Authors' calculation. 
2014 thirteen, out of 26 EU countries, have the value of composite indicator that equals 1 . One example is Malta is efficient country due to a sufficient weight that is assigned to the sub-indicator 'Recovery rate of construction and demolition waste. However, Malta, is so called weak-efficient, needs to improve each out of seven remaining sub-indicators since, is among the countries with their lowest. On the other hand, Bulgaria and Ireland are among efficient countries thus only rated based on the highest value they have for one subindicator with a sufficiently high value. Also, there are several countries with which are efficient only based on sufficiently high values for two sub-indicators.

To eliminate the obvious shortcomings, we have created Scenario 2, where the maximum virtual value of each sub-indicator is bounded by 0.25 in model (Eq. 7). This way, it enables a country to be efficient and to have WMCI value equals to, only if it has high values for minimum four sub-indicators. The results have shown ten countries being efficient in the year 2014. Nevertheless, it can be noticed that for some efficient countries, the influence of the RRI is almost neglected (for example Bulgaria RRI is 0.09, and for Portugal RRI is 0.20).

Scenario 3 solves the abovementioned issue by introducing additional restriction that the value of the indicator RRI (Eq. 6 in the model 4-8) must be at least 0.3 . The obtained results are shown in Table 3 for all monitored years.

It can be seen from Table 3 that only four countries are fully efficient in for all four years and these are Austria, Belgium, the Netherlands and Germany. Furthermore, those countries that have been efficient three times are Denmark, Sweden and Slovenia. Still, the countries that have not been efficient for a single year, but have always been ranked among the top ten, are Italy and Ireland. Also, the country with the highest growth of DEA WMCI is Lithuania (the value of DEA WMCI is 0.387 for 2010, to be efficient in 2016 with a value of 1 for DEA WMCI). However, the countries that are not well ranked but have a steady growth of DEA WMCI are Finland, Hungary and Slovakia. Finally, the countries ranked worst according to the DEA WMCI are Malta and Romania, followed by Cyprus and Estonia.

Table 4, shows the values obtained for the RRI and RSWSI calculated by the left-hand side of Eq. (6). The maximum value of RRI equals 0.5.

According to the RRI the country with the highest value are: the Netherlands, Belgium and Austria, and the top ranked ones also include: Slovenia, Great Britain, Luxembourg, Denmark, Sweden, Lithuania, Germany. Considering the RSWSI, the best ranked country is Germany, followed by Ireland and Italy. Among the top ranked countries are Sweden, the Czech Republic, Denmark, Luxembourg, Portugal and Slovenia. Furthermore, the maximum value of RSWSI equals 0.7. Figure 1. shows share of RRI and RSWSI in WMCI in 2016. According to the results, the contributions of indicators to WMCI are balanced for all the best ranked countries except the Germany, with predominant RSWSI value of 0.7 . This could be used as a direction for less developed countries in the waste management area.

\section{Discussion}

To check the stability of the WMCI values, we performed another experiment (Scenario 4) by including the following restrictions to our DEA-based model (4-8):

1. The maximum value of both indicators, the RRI and the RSWSI equal 0.5 (Eqs 6)

2. The minimum virtual value for each sub-indicator equals 0.03 (Eq. 7).

The first restrictions provide an equal impact of RRI and RSWSI on the formation of the WMCI. The second restriction ensures that in achieving the goal of maximizing the WMCI, the impact of sub-indicators cannot be completely ignored if a country had low values. Upon solving the model, it was obtained that the WMCI value of 1 is achieved during all four years only for Germany, the Netherlands and Austria. Belgium occupies rank four, with WMCI equals to 1 for 2012, 2014, and 2016. However, it has WMCI equals 0.926

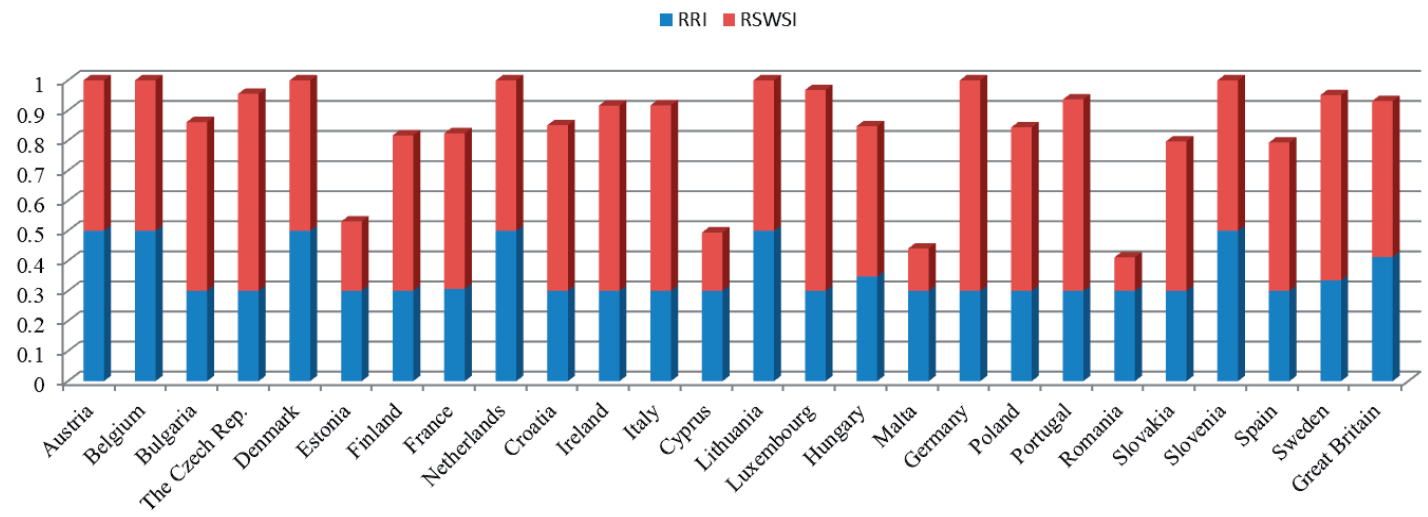

Fig. 1. Share of RRI and RSWSI in WMCI in 2016 (Source: Authors' calculation). 
for 2010 due to a small value for the Recovery rate of construction and demolition waste 17\%). Also, if we take a look at another ranking positions, we see that Denmark, Sweden and Luxembourg occupy from the $5^{\text {th }}$ to $7^{\text {th }}$ place, which is the same as in Table 3. Finally, Italy, Great Britain, Slovenia and Ireland are ranked from the $8^{\text {th }}$ to $11^{\text {th }}$ position, which also coincides with the ranks in Table 3 differing only in the position order, i.e., Slovenia, Ireland, Italy and Great Britain.

After comparing the result of this Scenario 4 with the results of Scenario 3 shown in Table 3, we can see that the rankings significantly varied only for four countries. For example, the values of the WMCI are quite lower for the Czech Republic, which used to be ranked 12 (Table 3) whereas, it declined to $21^{\text {th }}$ rank since it has been forced to consider very low value of sub-indicator Recycling of biowaste per capita. Besides, the values WMCI are also significantly lower for Poland which declined from rank 17 (Table 3) to 22. The reason is that Poland has low values of the subindicators Recycling rate of total packaging waste, the Recycling rate of plastic packaging waste and Recycling of biowaste per capita. Therefore, those sources of 'inefficiencies' could be seen as a weakness of each individual country and set the directions for further development and improving the specific sub-indicator. However, countries such as Estonia (rank rise from 23 to 18) and Romania (rank rise from 25 to 20) have a significantly better ranking in comparison to the results shown in Table 3.

Given that the same or similar results of ranking positions were achieved for the remaining twenty-two countries, this experiment confirmed the reliability of the results shown in Table 3. The seven first-ranked countries in both illustrations primarily are Germany, the Netherlands and Austria, followed by Belgium, Denmark, Sweden and Luxembourg, Making these countries a suitable example of best practice within the Waste management area. Also, the results obtained by the model proposed in this paper are similar to those obtained by Cavicchia, Sarnacchiaro and Vichy [56] who developed the CI composite index for Waste Management in Europe by using Hierarchical Disjoint Non-Negative Factorial Analysis (HDNFA). As conclusion, Scenario 3 is accaptable for WMCI evaluation and monitoring and further below, we will discuss the achievement of the top four countries according to its results.

The CE policy was developed by the Dutch government in 2016, and it focuses on five manufacturing sectors: construction, industry, consumer goods, plastics, and organic waste [57]. Therefore, when speaking about the Waste management area, which is the key to achieving sustainable resource management, the Netherlands has been 'far ahead of EU waste management policy and has had more or less influence over European policies formulated in recent years' [58]. Hence, significant technological advances in the area of converting waste into valuable resources have been achieved in the Netherlands, while recycling is still the most desirable option for waste management [58]. Furthermore, according to the results shown in Table 4 and Fig. 1, the Netherlands is the best in Europe when it comes to the RRI, whereas the data confirms that the Netherlands is among the best countries in Europe for 5 out of 8 sub-indicators. This all could be explained by the affirmation that the Netherlands 'focuses on high-quality recycling, incineration with increased efficiency as well as the highest quality use of recyclable materials' [59]. Consequently, in recent years, the Netherlands has managed to divert more than half of the waste produced in 2010 to recycle materials and organic products. Out of the total number of 9.8 million tonnes of waste produced in 2010, 5 million tonnes were recycled and 3.2 million tonnes incinerated (with or without energy recovery), whereas only 0.03 million tonnes ended up in landfills [58]. Hence, the fact that in the year 2013 the Netherlands recycled $78 \%$ of its total waste, incinerated $19 \%$ and discarded only 3\% [60] is an explanation for its leading positions when it comes to recycling in the EU.

Furthermore, there is Germany as one of the top four countries according to WMCI. It is also one of the country with a high-voltage industry, but which encourages recycling by providing various facilities; good financing for recycling, as well as various monetary incentives. Recycling and technology are at a high level in Germany, meaning that legislation, regulations, prohibitions, restrictions alongside other instruments are clearly and strictly established.

Therefore, it does not come as a surprise that on a world level Germany, along with China and Japan, is considered a pioneer in the implementation of the CE. This stems from the fact that this country has had a long-lasting experience with effective strategies development by establishing strict goals and ground rules in the Waste management area, but simultaneously remaining closely related to the concept of CE [61]. In the final years of the 1980s, Germany had upgraded its efficiency in waste management by introducing and improving waste collection and sorting methods during this period.

Also, an efficient waste management system, which focuses primarily on prevention, in terms of waste sorting and sorting; waste sorting and processing technologies; as well as recycling, is at a very high level in Germany. The action that most certainly stands out is the recycling of municipal waste. Hence, according to Eurostat data, [53] data taken from 2010 (62.5\%) to $2016(67.1 \%)$ show constant growth in this area. All these results are the reflections and consequences of a gradually introduced and basic system of behaviour, both within the state system and individual behaviour [53]. Moreover, Germany is the leader in the EU according to the sub-indicator Total recycling rate of total packaging waste. Finally, it might be said that in future Germany should work on reducing the use of primary raw materials, i.e., on trying not to lose a lot of 
value from secondary raw materials from the recycling process, rather than to find ways to return them to the production system.

Furthermore, when it comes to Austria as on of WMCI top four, it seems that this country has achieved significant results in the application of the $\mathrm{CE}$, in terms of their mindset; infrastructure for the use of waste as a resource; but also for setting ambitious goals in terms of prioritising the resource regeneration. Moreover, alongside Germany, it ranks among the global leaders in recycling. Meaning that Austria's commitment to upgrade and improve its waste management for almost four decades has resulted in 58\% of municipal waste being recycled [62]. The Austrian market is also in a leading position and this country is the best in Europe according to the sub-indicator Recycling of biowaste per capita.

Hence, Austria and Germany have been awarded first place in the EU by the EU Commission upon recognizing the high standards of waste management implemented in these two countries [63].

The last country out of the top four in the EU is Belgium. It supports the United Nations Environment Programme (UNEP) intercession to accelerate the transition to resource-efficient and sustainable economies. One of the goals of the CE model is achieving zero waste, meaning that all materials are constantly in circulation, and this is what Belgium strives for in the future. Moreover, in this country, the recycling costs are fully supported by the industry [54], and in 2016 Belgium ranked second in the EU (after Slovenia) in waste recycling, with almost $77 \%$ of total waste recycled [64]. The waste policy here includes a combination of different instruments, such as awareness-raising, recycling fees, disposal bans.

This country has implemented the principle named 'polluter-pays' which strictly refers to the weight of the generated waste and based on which Belgium has managed to achieve good results in the area of waste management [13]. Moreover, the aforementioned principle might be a good indicator, especially for developing countries and for those countries that the waste management system has not been adequately developed yet.

Finally, based on the results shown in Table 4 and Fig. 1, it can be seen that Belgium is among the best in the EU according to the RRI. Whereas based on the data it can be seen that Belgium is among the best countries in the EU according to the Recycling rate of total packaging waste and the Rate of recycling of wooden packaging even though it is ranked among the worst countries according to the Construction and demolition waste recovery.

\section{Conclusions}

The CE, as a concept and a business model, represents global changes at all levels, changes in the way raw materials are used, innovations in the production, consumption and finally the creation and reuse of waste, returning it to the production process. Waste management represents only one part of the areas within the CE, still, numerous resources might be saved with its appropriate implementation, but it would also contribute to the development of further foundations for the implementation of the CE principles and models.

In this paper, we developed two-layer CE composite indicator in the Waste Management area (WMCI) by using the tailored-made DEA-based model. The proposed model enables defining the range of individual indicators influence (RRI and RSWSI) on WMCI, as well as defining the lower and the upper bound of influence for each of the 8 sub-indicators. These parameters were established combining the experts' opinion and validation of experimental results. The advantage of the approach proposed in this paper lays in the following: the ability to include different type of indicators and sub-indicators with different type of the measurement units, the ability to evaluate composite index (WMCI) together with its building indicators (RRI and RSWSI), the ability to determine the influence of each indicator and sub-indicator without assumptions of the exact weights.

The WMCI values indicate that the Netherlands, Germany, Austria and Belgium are the most developed countries in the Waste Management area. Considering the fact that the CE model is complex and that the transition from a linear to a circular model is a long-lasting process, the implementation of the $\mathrm{CE}$ principle in each EU country has reached different levels in different areas. The reason for this could be found in the diversity of the countries, which includes their different cultures, with dissimilar economies, industries, different raw materials. Thus, all of this leads to unequal opportunities and limits within which the CE principles could be implemented.

However, what is common to the aforementioned countries, especially to Germany and the Netherlands, is they had established their waste management systems over thirty years ago. Also, we cannot discard the fact that their focus on environmental protection and environmental awareness has been one of the priorities dealt with in their societies, putting it significantly on a higher level than those EU countries that have shown results of less quality. Although these EU countries differ in the economy, culture, technology as well as in matters of waste management, this paper presents a clear division between the areas in which these countries have proven to be efficient. Hence, Germany and Austria are in the leading positions in terms of technology and high-quality recycling, whereas the Netherlands and Belgium are more focused on the reuse of secondary raw materials obtained through recycling. Nevertheless, Germany and Austria have a small percentage of returning resources to the economy, i.e. to the re-production process. On the other hand, the actions taken by the Netherlands and Belgium emphasize the 
best use of the recovered materials, meaning that these two countries have made significantly better progress in terms of using the secondary raw materials waste.

Therefore, the contribution of the research is not only reflected in understanding the development of the composite indicator WMCI, which enables the analysis and ranking of the EU countries in the waste management field, but its importance is also pondered in the fact that each country can be individually analyzed according to each used sub-indicator, i.e. according to the information about its current situation and the level it has reached, focusing on more efficient and less efficient areas. At the same time, the countries gain guidelines and direction for undertaking further actions, alongside the opportunities for improving those sub-indicators that are less efficient, but also for upgrading those sub-indicators that have had their efficiency demonstrated.

Finally, the obtained results provide a precise starting point for developing some further research and analyses. This also stipulates a quite good basis for recognizing those areas where it is necessary for countries to further develop their renewable capacities and potentials, to reorient their strategies and policies, for them to meet the established goals of efficient waste management while the CE principles. Therefore, certain future guidelines and recommendations refer to the fact that, based on some similarities or differences, the EU countries may try applying and implementing some of the examples of good practice of those countries that have shown so far the greatest efficiency. This would further influence them to develop the waste management area, alongside the implementation and application of the CE.

\section{Conflict of Interest}

The authors declare no conflict of interest.

\section{References}

1. MilANOVIĆ T., PETROVIĆ N., ĆIROVIĆ M. Waste management and circular economy. Proceedings of the XII Conference of Business and Science SPIN '19: Lean transformation and digitalization of Serbian industry. Faculty of Organizational Sciences, Belgrade, Serbia, 328, 2019 [In Serbian].

2. GOLSTEIJN L., VALENCIA MARTINEZ, E. The circular economy of E-waste in the Netherlands: optimizing material recycling and energy recovery. J. Eng., 6, 2017.

3. PETROVIC N.B., SAVIC G., ANDRIJASEVIC D., STANOJEVIC M., CIROVIC M., SLOVIC D., RADAKOVIC J.A. Evaluating eco-efficiency of beverage packaging materials: a data envelopment analysis approach. Fresenius Environ. Bull., 25 (2016), 2958, 2016.

4. EEA - European Economic Area. Circular economy in Europe. Developing the knowledge base. Report No 2. European Environment Agency, Copenhagen K, Denmark ISSN 1977-8449. 2016.
5. MACARTHUR E. Towards the circular economy, economic and business rationale for an accelerated transition. Ellen MacArthur Foundation, Cowes, UK. Available online: https://www.ellenmacarthurfoundation. org/assets/downloads/publications/Ellen-MacArthurFoundation-Towards-the-Circular-Economy-vol.1.pdf. 2013. (Accessed on 11. 06. 2020).

6. HISLOP H., HILL J. Reinventing the wheel: a circular economy for resource security. Green Alliance. Green Alliance, London, 4, 2011.

7. EC - EUROPEAN COMMISSION. Closing the loop: Commission adopts ambitious new Circular Economy Package to boost competitiveness, create jobs and generate sustainable growth. Brisel. Available online: https:// europa.eu/rapid/press-release_IP-15-6203_en.htm.2015. 2015. (Accessed on 05. 07. 2020).

8. HUANG Y., ZHANG Y. Energy Use and Carbon Emissions Efficiency Study of Chinese Regions Based on Price Factor. Pol. J. Environ. Stud., 27 (5), 2059, 2018.

9. GARCIA-BERNABEU A., HILARIO-CABALLERO A., PLA-SANTAMARIA D., SALAS-MOLINA F. A Process Oriented MCDM Approach to Construct a Circular Economy Composite Index. Sustainability., 12 (2), 618. 2020.

10. MILANOVIĆ T., JOVOVIĆ A., PETROVIĆ N., MARTIĆ M. Overview of circular economy indicators of developed countries. Proceedings of the XLVII International Symposium on Operational Research, SYM-OP-IS 2020. Faculty of Transport and Traffic Engineering. University of Belgrade, Belgrade, Serbia, 17, 2020. [In Serbian].

11. SAIDANI M., YANNOU B., LEROY Y., CLUZEL F., KENDALL A. A taxonomy of circular economy indicators. J. Clean. Prod., 207, 542, 2019.

12. IACOVIDOU E., VELIS C.A., PURNELL P., ZWIRNER O., BROWN A., HAHLADAKIS J., WILLIAMS P.T. Metrics for optimizing the multi-dimensional value of resources recovered from waste in a circular economy: A critical review. J. Clean. Prod., 166, 910, 2017.

13. GIANNAKITSIDOU O., GIANNIKOS I., CHONDROU A. Ranking European countries on the basis of their environmental and circular economy performance: A DEA application in MSW. Waste Manag., 109, 181, 2020.

14. MITROVIĆ Đ., VESELINOV M. Measuring countries competitiveness in circular economy-composite index approach. Quantitative Models in Economics. University of Belgrade, Belgrade, 417, 2018.

15. NARDO M., SAISANA M., SALTELLI A., TARANTOLA S., HOMAN A., GIOVANNINI E. Handbook on constructing composite indicators: Methodology and user guide. OECD statistics working papers 2005/3, OECD, statistics directorate, French 12-14. 2005.

16. VIDOLI F., FUSCO E., MAZZIOTTA C. Noncompensability in composite indicators: A robust directional frontier method. Soc. Indic. Res., 122 (3), 635, 2015.

17. SYP A., FABER A., BORZECKA-WALKER M., OSUCH D. Assessment of Greenhouse Gas Emissions in Winter Wheat Farms Using Data Envelopment Analysis Approach. Pol. J. Environ. Stud., 24 (5), 2197, 2015.

18. SAVIĆ G., MARTIĆ M. Composite indicators construction by data envelopment analysis: Methodological background. In Emerging Trends in the Development and Application of Composite Indicators. IGI Global, 98, 2017.

19. ZHOU P., ANG B. W. Comparing MCDA aggregation methods in constructing composite indicators using the Shannon-Spearman measure. Soc. Indic. Res., 94 (1), 83, 2009. 
20. MILANOVIĆ T., PETROVIĆ N., MILANOVIĆ, M. Sustainable development indicators of the Republic of Serbia, Proceedings of the XIV International Symposium SymOrg 2014: New Business Models and Sustainable Competitiveness Management and Business Performance. Faculty of Organizational Sciences, Belgrade, Serbia, 1663, 2014.

21. EC - EUROPEAN COMMISSION. Communication from the Commission to the European Parliament, the Council, the European Economic and Social Committee and the Committee of the Regions. 2015.

22. EC - EUROPEAN COMMISSION. Circular Economy Indicators. Available online: https://ec.europa.eu/ environment/ecoap/indicators/circular-economyindicators_en. (Accessed on 20. 02 2020).

23. EC - EUROPEAN COMMISSION. Closing the loop - An EU action plan for the Circular Economy COM (2015) 614 final. Brisel. 2015.

24. GRONBA-CHYLA A., GENEROWICZ A., KRAMEK A. Using Selected Types of Waste to Produce New Light Ceramic Material. Pol. J. Environ. Stud., 30, (3), 2073, 2021.

25. VELEVA V., BODKIN G., TODOROVA S. The need for better measurement and employee engagement to advance a circular economy: Lessons from Biogen's 'zero waste' journey. J. Clean. Prod, 154, 517, 2017.

26. OECD - Organization for Economic Cooperation and Development. Handbook on Constructing Composite Indicators. Methodology and user guide, ISBN 978-92-6404345-9 - C OECD. 2008.

27. MIZOBUCHI H. Measuring world better life frontier: a composite indicator for OECD better life index. Soc. Indic. Res., 118 (3), 987, 2014.

28. CHERCHYE L., MOESEN W., ROGGE N., VAN PUYENBROECK T.V. An introduction to 'benefit of the doubt' composite indicators. Soc. Indic. Res., 82 (1), 111, 2007.

29. GRECO S., ISHIZAKA A., TASIOU M., TORRISI G. On the methodological framework of composite indices: A review of the issues of weighting, aggregation, and robustness. Soc. Indic. Res., 141, 61, 2019.

30. RUIZ F., EL GIBARI S., CABELLO J.M., GOMEZ T. MRP-WSCI: Multiple reference point based weak and strong composite indicators. Omega. 95, 102060, 2020.

31. MITROVIĆ Đ., GAVRIĆ, O. Circular economy composite index: DEA approach. Proceedings of the XLV International Symposium on Operational Research, SYMOP-IS 2018. Faculty of Economy. University of Belgrade, Belgrade, Serbia, 250, 2018.

32. GAVRIĆ O., MITROVIĆ Đ. Development of Green Economy and competitiveness of EU countries: Macrolevel empirical analysis. Ekonomika preduzeća., 67 (7-8), 415, 2019.

33. LI B., XU J. An evaluation model based on data envelopment analysis and its application to county circular economy. WJMS., 4 (1), 35, 2008.

34. CHEN F., YAO W. Evaluation of Circular Economy Efficiency in Eastern China. IOP Publishing. In IOP Conference Series: Environ. Earth Sci., 453 (1), 012030, 2020.

35. LO STORTO C. Ecological efficiency based ranking of cities: A combined DEA cross-efficiency and Shannon's entropy method. Sustainability., 8 (2), 124. 2016.

36. HALKOS G., PETROU K. N. Assessing 28 EU member states' environmental efficiency in national waste generation with DEA. J. Clean. Prod., 208, 509, 2019.
37. CRISTOBAL J., LIMLEAMTHONG P., MANFREDI S., GUILLEN-GOSALBEZ G. Methodology for combined use of data envelopment analysis and life cycle assessment applied to food waste management. J. Clean. Prod., 135, 158, 2016.

38. SARRA A., MAZZOCCHITTI M., RAPPOSELLI A. Evaluating joint environmental and cost performance in municipal waste management systems through data envelopment analysis: Scale effects and policy implications. Ecol. Indic., 73, 756, 2017.

39. TABOADA G.L., SERUCA I., SOUSA C., PEREIRA Á. Exploratory data analysis and data envelopment analysis of construction and demolition waste management in the European Economic Area. Sustainability., 12 (12), 4995, 2020.

40. ASTILLO-GIMENEZ J., MONTANES A., PICAZOTADEO A. J. Performance and convergence in municipal waste treatment in the European Union. Waste Manag., 85, 222, 2019.

41. HUANG Y.T., PAN T.C., KAO J.J. Performance assessment for municipal solid waste collection in Taiwan. J. Environ. Manage., 92 (4), 1277, 2011.

42. ZANELLA A., CAMANHO A.S., DIAS T.G. Undesirable outputs and weighting schemes in composite indicators based on data envelopment analysis. Eur. J. Oper. Res., 245 (2), 517, 2015.

43. WANG H. A generalized MCDA-DEA (multi-criterion decision analysis-data envelopment analysis) approach to construct slacks-based composite indicator. Energy., 80, 114, 2015.

44. ATHANASSOGLOU S. Revisiting worst-case DEA for composite indicators. Soc. Indic. Res., 128 (3), 1259, 2016.

45. SHEN Y., HERMANS E., BRIJS T., WETS G. Data envelopment analysis for composite indicators: A multiple layer model. Soc. Indic. Res., 114 (2), 739, 2013.

46. CHARNES A., COOPER W. W., RHODES E. Measuring the efficiency of decision making units. Eur. J. Oper. Res., 2 (6), 429, 1978.

47. TSAI W.H., LEE H.L., YANG C.H., HUANG C.C. InputOutput Analysis for Sustainability by Using DEA Method: A Comparison Study between European and Asian Countries. Sustainability., 8 (12), 1230, 2016.

48. EMROUZNEJAD A., YANG G.L. A survey and analysis of the first 40 years of scholarly literature in DEA: 19782016. Socio-Econ. Plan. Sci. 61, 4, 2018.

49. YU M.M. An integration of the multi-component DEA and GAR models to the measurement of hotel performance. Curr. Issues Tour., 15 (5), 461, 2012.

50. SARRICO C.S., DYSON R.G. Restricting virtual weights in data envelopment analysis. Eur. J. Oper. Res., 159 (1), 17, 2004.

51. RADOJIČIĆ M., SAVIĆ G., JEREMIĆ V. Measuring the efficiency of banks: the bootstrapped I-distance GAR DEA approach. Technol. Econ. Dev. Econ., 24 (4), 1581, 2018.

52. POPOVIĆ M., SAVIĆ G., KUZMANOVIĆ M., MARTIĆ M. Using data envelopment analysis and multi-criteria decision-making methods to evaluate teacher performance in higher education. Symmetry., 12 (4), 563, 2020.

53. EC - EUROPEAN COMMISSION. Commission Staff Working Document measuring progress towards circular economy in the EU - key indicators for a monitoring framework, Strasbourg, SWD (2018) 17 final. Available online: https://eur-lex.europa.eu/legal-content/EN/ TXT/?uri=SWD:2018:17:FIN. 2018. (Accessed on 05. 04. 2020). 
54. MARQUES R.C., DA CRUZ N.F., SIMOES P., FERREIRA S.F., PEREIRA M.C., DE JAEGER S. Economic viability of packaging waste recycling systems: A comparison between Belgium and Portugal. Resour Conserv Recycl., 85, 22, 2014.

55. AWASTHI A.K., LI J., KOH L., OGUNSEITAN O.A. Circular economy and electronic waste. Nat. Electron., 2 (3), 86, 2019.

56. CAVICCHIA C., SARNACCHIARO P., VICHI M. A composite indicator for the waste management in the EU via Hierarchical Disjoint Non-Negative Factor Analysis. Socio-Econ. Plan. Sci., 73, 100832, 2021.

57. VAN LEEUWEN K., DE VRIES E., KOOP S., ROEST $\mathrm{K}$. The energy \& raw materials factory: Role and potential contribution to the circular economy of the Netherlands. Environ Manage., 61 (5), 786, 2018.

58. EEA - EUROPEAN ENVIRONMENT AGENCY. Municipal waste management in the Netherlands, Leonidas Milios, EEA project manager Almut Reichel. 2013.

59. CORSTEN M., WORRELL E., ROUW M., VAN DUIN A. The potential contribution of sustainable waste management to energy use and greenhouse gas emission reduction in the Netherlands. Resour Conserv Recycl., 77, 13,2013
60. RIJKSWATERSTAAT. Dutch Waste in Figures: Data for 2006-2010. Utrecht: Rijkswaterstaat, Minister van Infrastructuur en Waterstaat, Nederland. 2013.

61. OGUNMAKINDE O.E. A review of circular economy development models in China, Germany and Japan. Recycling., 4 (3), 27, 2019.

62. CIRCLE ECONOMY \& ARA 2019. The Circularity Gap Report Austria - 2019, Closing the Circularity Gap in Austria, June 2019. Available online: https://www.ara. at/fileadmin/user upload/Downloads/Circularity_Gap Report/CGR_Austria_Endversion.pdf. 2019. (Accessed on 30. 03. 2020)

63. EUROPEAN ENVIRONMENTAL BUREAU (EEB) \& EUNOMIA. Recycling - who really leads the world? Available online: https://eeb.org/new-researchchallengescountries-reporting-highest-recyclingrates/. (Accessed on 25.10. 2020).

64. UNEP - UNITED NATIONS ENVIRONMENT PROGRAMME. Belgium, on its way towards a circular economy. Available online: https://www.unep.org/newsand-stories/story/belgium-its-way-towards-circulareconomy. (Accessed on 31.10. 2020). 